\title{
$\mathrm{RDA}$ 자원유형의 $\mathrm{KCR} 4$ 적용에 관한 연구
}

\section{A Study on Application of Resource Types of RDA to KCR4}

\author{
이미화(Mihwa Lee)*
}

\begin{abstract}
초 록
본 연구는 RDA 자원유형을 $\mathrm{KCR} 4$ 에 적용하기 위한 방안을 모색하기 위한 것이다. KCR4의 $\mathrm{GMD}$ 는 내용과 용기의 용어가 혼합되어 적합한 용어를 선정하기 어렵고, $\mathrm{FRBR}$ 개념모형 구현도 용이하지 않다. $\mathrm{SMD}$ 도 이용자의 요구에 맞는 최신의 용어가 포함되지 않아 변경이 필요한 실정이다. 기 개발된 RDA 자원유형은 $\mathrm{AACR} 2 \mathrm{GMD}$ 의 한계를 극복하기 위해 다양한 용어의 측면을 고려하였고, 앞으로 목록분야에 많은 영향을 줄 수 있다. 따라서 국내 목록환경에 $\mathrm{RDA}$ 자원유형의 적용가능성이 모색되어야 할 것이다. 이를 위해 사례조사, 설문조사를 실시하였으며, 사례조사는 국내 대학도서관 한 개 기관을 대상으로 GMD 기술의 전수조사를 실시하여 용어의 변경 및 사서 및 이용자가 원하는 용어의 방향을 파악하였다. 설문조사에서는 국내 대학도서관 사서를 대상으로 자원유형 기술의 현황과 문제점 및 $\mathrm{RDA}$ 자원유형 이해정도를 파악하였다. 조사결과 자원유형 용어는 검색과 기술을 위해 구체적이고 이용자가 이해하기 쉬운 용어로 변경이 필요하였다. RDA 적용 테스트에서는 자원유형에 따라 정답률에 차이가 있었다. 조사를 바탕으로 RDA 내용유형에 컴퓨터게임을, 용기유형에 DVD, CD-ROM, Blu-Ray, 컴퓨터파일을 추가하여 $\mathrm{KCR} 4$ 의 자원유형을 제안하였다. 기술방식과 화면출력에서도 RDA의 방식을 제안하였다. 본 연구는 $\mathrm{RDA}$ 자원유형의 국내 적용가능성을 모색하여, $\mathrm{KCR} 4$ 자원유형 개정의 기반을 마련하였다.
\end{abstract}

\begin{abstract}
This study is to seek to apply resource types of RDA to KCR4. It is difficult to choose appropriate term and to embody FRBR model because GMD of KCR4 is the mixture of content-based vocabularies and carrier-based vocabularies. SMD is to need to reflect the current technological terms. Resource type of RDA was already developed to overcome limitation of AACR2's GMD, and would affect the world cataloging environment, therefore it is need to apply resource type of RDA to Korean cataloging rule. For this study, case study and survey were used. In case study, it was to scan all GMD term for one university library to build by programming and to grape librarian and users' potential need. In the survey by cataloging librarian, it was to figure out the current description of resource type in university library and to test RDA resource type. As a result, it was needed to revise the vocabulary to the obvious and user-understandable list. Also it was different in correction rate in RDA testing by resource type. Based on the case study and the survey, RDA resource type was applied to KCR4 resource list by adding term such as computer game in content type, and by inserting terms such as DVD, CD-ROM, Blu-Ray, computer file in carrier type. It also applied RDA description method and display means to KCR4. This study would apply RDA resource type to KCR4 and contribute to revise KCR4 resource type.
\end{abstract}

키워드: 서지레코드의 기능적요건, 자원기술과 접근, 영미목록규칙, 한국목록규칙, 내용유형, 매체유형, 용기유형, 자료유형, 특정자료종별

FRBR, RDA, AACR2, KCR4, content type, media type, carrier type, GMD, SMD

* 이화여자대학교 문헌정보학과 시간강사(leemh@hansung.ac.kr)

- 논문접수일자 : 2011년 7월 21일 - 최초심사일자 : 2011년 8월 16일 - 게재확정일자 : 2011년 9월 12일

- 정보관리학회지, 28(3): 103-121, 2011. [http://dx.doi.org/10.3743/KOSIM.2011.28.3.103] 


\section{1. 서 론}

\section{1 연구목적 및 방법}

자료유형(General Material Designator, GMD) 과 특정자료종별(Specific Material Designator, $\mathrm{SMD})$ 등의 자원유형은 검색 시 자원의 선정을 위 한 중요한 정보이며, 서지기술 시에도 자원에 따라 기술요소를 달리하는 정보로 사용되어왔다. 최근 자원유형은 $\mathrm{FRBR}$ 개념모형의 저작, 표현형 기술 을 위한 핵심 요소로 그 중요성이 대두되고 있다.

이에 따라 AACR2를 대체할 Resource $\mathrm{De}^{-}$ scription and Access(RDA, 자원의 기술과 접 근)에서는 내용유형 기술을 위한 용어를 새롭게 고안하였고, 매체유형이라는 유형을 추가하였으 며, 용기유형을 이용자에 맞게 최신 용어로 변경 하였다. 즉 기존 $\mathrm{AACR} 2$ 내의 $\mathrm{GMD}$ 와 $\mathrm{SMD}$ 를 해체하고, 이를 내용유형, 매체유형, 용기유형으 로 새롭게 재구성하였다.

$\mathrm{RDA}$ 의 자원유형 기술에 맞게 입력형식인 MARC21도 갱신되었다. 기존 $245 \$ \mathrm{~h}, 300 \$ \mathrm{a}$ 를 대체하여 자원의 내용유형을 $336 \$ \mathrm{a}$, 매체 유형을 $337 \$ a$, 용기유형을 $338 \$ a$ 에 각각 기 술하도록 규정하였다.

이러한 과정은 FRBR 개념모형 구현을 위해 서지세계에서 목록규칙과 입력형식의 변화이 며, 궁극적으로는 이용자가 쉽게 자원을 검색하 고 선택할 수 있도록 하기 위함이다.

그러나 국내에서 자원유형 기술할 때 $\mathrm{KCR} 4$ 와 $\mathrm{KORMARC}$ 의 용어 리스트를 기관마다 다 양하게 적용하고 있으며, 이러한 리스트에는 내용유형과 용기유형의 용어가 혼합되어 있어 적합한 자원유형을 적용하기 어렵게 한다. 이
는 검색에도 영향을 주어 자원유형 용어로 이 용자는 자신이 원하는 자료인지 판단하기 어렵 다. 뿐만 아니라 기존의 자원유형은 $\mathrm{FRBR}$ 개 념모형 구현을 위해서도 적합하지 않다. 따라 서 한국목록규칙의 자원유형에 대한 개정이 필 요한 시점이며, 국내에서 RDA의 내용유형, 매 체유형, 용기유형을 변형 적용하는 방법이 고 려되어야 할 것이다. 왜냐하면 이미 RDA 자원 유형 용어 리스트가 AACR2 자원유형의 한계 를 파악하고 다양한 측면을 고려하여 오랜 기 간의 연구를 통해 개발되었으며, RDA의 용어 가 앞으로 목록분야에 많은 영향을 줄 수 있기 때문이다. 또한 국내에서 양서를 목록할 때 영 미목록규칙을 따르기 때문이다. 따라서 자원유 형 용어를 개발하기 위해 $\mathrm{RDA}$ 용어에 대한 국 내 적용 가능성을 타진하는 것이 필요하겠다. 이에 본 연구는 FRBR 개념모형을 구현하고, 이용자의 검색 시 도움이 될 수 있는 자원유형 리스트를 개발하기 위해 문헌연구, 사례조사, 설 문조사를 실시하여 $\mathrm{RDA}$ 자원유형의 국내 적용 가능성을 조사하였다. 문헌연구를 통해 자원유 형에 관한 개념과 $\mathrm{RDA}$ 의 자원유형을 살펴보고 사례조사로 대학도서관에서 실재 $\mathrm{GMD}$ 입력 현 황을 파악하여 현장의 요구를 파악하였다. 설문 조사를 통해 국내에서 자원유형 기술 현황, 문 제점 및 개선방안, 기 개발된 RDA 용어리스트 에 대한 사서의 이해정도를 파악하였다. 설문조 사는 국내 대학도서관중 장서수가 50 만권 이상 인 곳 50 개 기관을 선정하고, 목록사서에게 전자 메일과 전화를 이용해 전자설문을 요청하였다. 설문기간은 6 월 7 일부터 30 일까지였으며, 회신 은 50 개 기관 중 18 기관에서 회신되어 회신율은 $36 \%$ 로 나타났다. 설문지는 기본사항(1-7), 자 
원유형 적용 현황(8-23), 자원유형 기술의 문제 점 및 개선방향(24-28), $\mathrm{RDA}$ 자원유형 테스트 (29-30)로 구성되었다.

\section{2 선행연구}

자원유형에 대한 연구는 $\mathrm{GMD}$ 이용현황 및 문 제제기에 관한 연구, 자원유형 범주화에 관한 연구, 자원유형에 대한 이용자 인식조사 연구가 있다.

GMD 이용현황 및 문제제기 연구로 Weihs (2000)는 AACR2의 GMD에 대한 이해도, 자 료유형 표현을 위한 8 가지 가능한 방법에 대한 사서들의 인식을 연구하였다. 조사 결과 가장 선호하는 자료유형 기술방식은 한정어를 이용 한 GMD 방식이었으며, GMD 선택을 위한 선 행테이블, 복합 GMD 기술방식 등으로 순위가 매겨졌다. 뿐만 아니라 사서들은 현재 GMD에 불만족하며, 자원의 경계표시(waring sign)으로 $\mathrm{GMD}$ 의 역할을 강조하였다.

Chung(2001)은 이용자 중심의 영상자료 목 록을 위한 방안으로 청구번호 내에 자료유형정 보를 기술하고, 주제명표목에 장르유형정보를 기술하는 방안을 마련하였다. GMD 자료유형 정보를 세분화하기 위해 타 도서관에서 자원유형 기술 사례를 분석하였다.

Guerrini(2004)는 GMD의 역사적 측면과 기 능의 고찰을 통해 현행 $\mathrm{GMD}$ 수정의 필요성을 제기하였다. GMD는 자원유형의 부류를 표현 하는 하이브리드 특성이 제공되지 않고, 다양한 자원유형 리스트가 존재하고 일부 용어가 비적 절하며, 자원의 특성을 반영하지 못하는 용어가 사용되며, 온라인목록에서 디스플레이의 측면 즉 기술방식에 한계가 있다고 지적하였다.
이용현황과 문제제기에 관한 연구는 주로 현 행 $\mathrm{GMD}$ 의 이용현황을 조사하여 문제점을 제 기하거나, 실재 GMD 활용 시 자료유형을 세분 화한 사례, $\mathrm{GMD}$ 를 역사적으로 고찰하면서 그 기능 측면에서 용어의 문제점을 제기한 것이었 다. 최근 $\mathrm{GMD}$ 에 자원의 용기를 표현하는 용어 를 기술하려는 경향이 많은데 이는 기존 $\mathrm{GMD}$ 용어가 이용자가 쉽게 접하고 이해할 수 있는 용어를 수록하지 않기 때문이다.

이러한 문제를 바탕으로 자원유형에 대한 새 로운 범주화에 관한 연구로 다음과 같은 연구가 있었다. Delsey(1998)는 FRBR 개념모형의 관 점에서 목록기술을 위해 $\mathrm{AACR}$ 규칙을 분석하 였다. 그는 물리적 포맷, 자료의 유형, 용기 형태 를 표현하는 $\mathrm{GMD}$ 용어의 하이브리드 특성을 지적하고, 기존 $\mathrm{GMD}$ 용어에 표현형 속성과 구 현형 속성이 혼용되어 있음을 밝혔다.

Tillett(2001)는 영국과 미국의 GMD 리스트 를 비교하고, Delsey의 분석을 리뷰하면서, 서 지기술 시 표현형 유형, 자원의 분류(class), 물 리적 포맷, 용기의 형태가 모두 기술되어 이용 자에게 적절하게 제공되어야 함을 주장하였다.

JSC Format Variation Working Group(2003) 은 JSC에 따라 서지레코드 내에 GMD를 표현 하는 방안을 연구하였다. GMD/SMD Working Group(2005)은 'broad content', 'specific content', 'broad carrier', 'specific carrier'로 자원의 내용 과 용기를 구분하여 기술하는 방안을 제안하였다.

Delsey(2006)는 자원 범주 체계를 위해 자 원의 지적 예술적 내용과 내용을 수록하는 수 단이라는 2 가지 속성의 집합을 정의하였다. 내 용 속성은 캐릭터, 감각, 차원, 움직임이고, 용 기 속성은 중개도구, 저장매체포맷, 용기포맷이 
었다. 이를 바탕으로 RDA의 내용, 매체, 용기 리스트를 제시하였다.

Kiorgaard(2006)는 자원의 내용과 용기의 속 성 집합, 속성의 하위 집합으로 값(values)을 이용해 자원의 범주를 구조화하는 방법을 제안 하였다.

Dunsire(2007)는 자원의 내용과 용기의 범주 화를 위해 RDA/ONIX의 자원범주화 프레임워 크를 제안하고, 이러한 프레임워크가 DC type, $\mathrm{CIDOC}$ 에도 적용될 수 있음을 분석하였다.

$\mathrm{Yee}(2007)$ 는 FRBR 개념모형에 맞도록 동 영상의 $\mathrm{GMD}$ 와 $\mathrm{SMD}$ 를 분석하였다. 그는 동 영상(moving image)의 $\mathrm{GMD}$ 를 전자자원, 영 화, 비디오녹화자료로 규명하고, 이중 영화, 비 디오녹화자료 2 가지는 동영상의 내용 측면의 용 어임을 밝혔다.

Weihs와 Howarth(2008)는 초기 GMD의 시 작에서부터 $\mathrm{RDA}$ 에 이르는 자원유형 기술을 위 한 다양한 노력을 역사적으로 기술하였다.

Green과 Fallgren(2007)은 자원의 내용과 용기의 두 가지 패싯은 구분되기 어렵고, 순수 한 지적 내용과 순수한 물리적 용기는 존재하지 만, 서지세계에서 다뤄지는 자료의 대부분은 내 용과 용기가 모두 적용되는 중간적 측면에 있음 을 밝혔다. 따라서 자원유형의 패싯을 구조화하 기 위해 여러 구현형을 재검토한 후 내용, 내용 의 생성, 내용의 기록, 출판/배포, 물리적 특성, 인식/이용, 관계의 7 가지 패싯으로 자원의 구분 을 제안하였다.

자원유형 범주화에 관한 연구는 자원유형의 문제제기를 바탕으로 궁극적으로 $\mathrm{RDA}$ 자원유 형을 도출하는 과정의 연구라고 할 수 있었다.

자원유형 용어에 대한 최종이용자 인식에 대
한 조사연구로 Hider(2009a)는 자유리스팅기 법(free-listing)을 적용하여 이용자의 인식을 조사하였다. 실험에서 이용자에게 정보자원의 포맷과 정보자원의 내용을 모두 나열하도록 요 청하였다. 그 결과 RDA에 존재하지 않는 용어 가 상당부분 차지하였는데, 약 $93 \%$ 의 용어는 RDA 내용 유형의 용어와 일치하지 않았다. 용 기 측면에서도 대부분은 RDA용어와 관련이 없 었으며, 약 7\%만이 RDA 리스트와 일치하였다. 이는 최종이용자가 내용과 용기라는 용어의 측 면 이외에 자원의 이용목적, 청중, 크기 등의 측 면을 고려하여 자원을 분류하였기 때문이었다. $\operatorname{Hider}(2009 \mathrm{~b})$ 는 2가지 카드소팅을 통해 최종 이용자가 자원의 내용과 용기의 유형을 RDA에 서 구분한 범주대로 인식하는지를 조사하였다.

선행 연구를 종합하면 $\mathrm{AACR} 2$ 자원유형의 한계가 2000년부터 논의되었으며, 이 논의의 최종적 결론은 $\mathrm{RDA}$ 의 내용, 매체, 용기의 자 원유형으로 구체화되었다고 볼 수 있다. RDA 자원유형의 용어 적합성 연구는 이용자 측면에 서 조사되었으며, 사서 측면에서는 이루어지지 않았다. 따라서 본 연구는 RDA 자원유형 용어 에 대한 사서 측면에서 이용가능성에 관한 연구 이며, 실질적인 이해 정도를 조사하여 용어의 문제점을 파악하고 우리나라 목록규칙에 적용 하려고 한 점에서 그 의의가 있겠다.

\section{2. $\mathrm{RDA}$ 자원유형}

\section{1 자원유형의 개념 및 기능}

서지기술시 자원유형은 내용유형과 용기유 
형의 2가지 측면을 가지며, 내용유형은 GMD로 MARC 245 h에 용기유형은 SMD로 MARC $300 \$ a$ 에 기술해왔다.

자원유형의 기능은 첫째, 이용자의 검색 지원 기능으로 자원유형정보를 통해 이용자가 자신 에게 필요한 자원인지를 판단할 수 있도록 한다. 둘째, 자원의 서지기술을 위한 기능으로 자원유 형에 따라 서지기술방식과 우선정보원이 다르 기 때문에 GMD를 통해 자원을 우선 구분하고 이에 따른 서지기술을 할 수 있도록 한다. 셋째, $\mathrm{FRBR}$ 개념모형에서 저작과 표현형 식별을 위 한 핵심요소로 내용유형이 사용되고 있고, 구현 형의 식별을 위해 용기유형이 사용될 수 있어 자원유형은 FRBR 개념모형을 구현하는 기능 을 한다(이미화 2011).

\subsection{GMD 자원유형의 한계}

자원의 내용유형과 관련된 리스트는 KCR4, $\mathrm{AACR} 2$ 의 목록규칙에 수록된 자료유형(GMD), MARC의 리더/06, 007/00형태범주용어리스 트(form category term list)이며, 자원의 용기 유형과 관련된 리스트는 KCR4, $\mathrm{AACR} 2$ 의 특 정자료종별(SMD), MARC의 007/01특정자료 형태용어리스트(Specific Material Form Term List) 가 있다. 하지만, 이러한 리스트마다 용어 가 서로 상이하고, 동일 용어 리스트 내에서도 내용과 용기를 표현하는 용어가 혼용되어 있어 자원유형 기술에 어려움을 주고 있다.

$\mathrm{KCR} 4$ 의 $\mathrm{GMD}$ 리스트에서 비디오녹화자료 와 영화를 분석하면 비디오녹화자료는 자원의 내용측면을 표현하며, 영화는 필름을 표현하기 위한 용기 측면의 용어이다. 또한 마이크로자료
는 용기만을 표현하는 용어라고 할 수 있다. 이 와 같이 GMD 내에 내용 측면과 용기 측면의 용어가 함께 수록되어 있어 자원유형 기술에 어려움을 주고 있다.

$\mathrm{AACR} 2$ 에서는 리스트 1, 2로 구분해 영국과 미국에서 각각 사용해 왔으며, AACR2 자원유 형도 용어 자체의 문제가 제기되었다. Chapman (2006)은 GMD의 용어, SMD의 용어는 자원에 대한 정보를 제공하기 위한 것이다. 이는 자원 유형에 따른 화면디스플레이를 통해 이용자가 원하는 자료를 검색 필터링하는 데 사용되었다. 하지만 $\mathrm{GMD}$ 의 용어와 $\mathrm{SMD}$ 의 용어는 시대에 맞게 변화되지 못하고 제한되었으며, 동일 리스 트 내에 표현하려는 측면이 다른 용어가 공존하 고 있다. 즉 $\mathrm{GMD}$ 에는 음악, 지도와 같이 내용 을 나타내는 용어와 점자, 필름스트립과 같은 용기를 나타내는 용어가 함께 포함되어 있다. 뿐만 아니라 기술의 변화로 다양한 용어가 만 들어지면서 $\mathrm{GMD}$ 의 용어 및 $\mathrm{SMD}$ 의 용어는 점 점 이용자의 이용관행을 맞추지 못하였다. 예 를 들어, SMD 자원유형에는 'sound cassette', 'videodisc'와 같은 공인된 용어가 포함되지만, 이용자가 공통적으로 사용하는 'audio tape', DVD 등의 용어는 포함되지 않았다.

이에 $\mathrm{RDA}$ 에서는 미래에 필요한 여러 용어의 사용과 기존의 내용과 용기 용어를 사용할 수 있 도록 $\mathrm{GMD}$ 의 용어, $\mathrm{SMD}$ 의 용어를 내용유형, 용기유형으로 대체하여 기술하도록 제안하였다.

\subsection{RDA 자원유형}

최근 FRBR 개념모형 구현을 위해 자원유형 정보가 중시되면서, $\mathrm{RDA}$ 에서는 자원유형 기 
술시 내용유형, 매체유형, 용기유형으로 구분하 여 기술하도록 하였다. 내용은 자원의 용기와 는 별도로 그 자원에 대한 실질적인 내용의 측 면에서 접근하며, 매체와 용기는 자원의 외형 적 특성을 나타내는 것으로 매체는 자원을 열 람하기 위해 필요한 매체정보를 기술하며, 용 기는 매체와 연계하여 실재 용기의 명칭을 기 술한다.

예를 들어, DVD에 수록된 영상자료는 내용 유형은 2 차원동영상이고, 매체유형은 비디오이 며, 용기유형은 비디오라는 매체유형 하에 있는 비디오디스크가 된다. 매체유형인 비디오는 동 영상을 플레이하는 모든 비디오장비를 일컫는 다. 반면, 동일한 영상자료가 MP3파일인 경우 내용유형은 2 차원동영상이지만, 매체는 컴퓨터 이며, 용기는 온라인자원이 된다. 위의 2가지 자 원은 2 차원동영상이라는 동일 내용유형으로 동 일 표현형이지만 비디오디스크, MP3라는 용기 가 다르기 때문에 구현형은 'online resrouce, videodisc가 된다.

$\mathrm{RDA}$ 내용유형, 매체유형, 용기유형의 입력 형식은 기존의 $245 \$ \mathrm{~h}, 300 \$ \mathrm{a}$ 를 대체하여 336 , 337,338 에 기술한다. 여러 자원이 혼합된 kit의 경우 기존에는 자료유형을 kit로 표시하였으나, $\mathrm{RDA}$ 에서는 336 태그를 반복 기술하도록 하여 다양한 멀티미디어 요소를 갖는 자원을 기술할 수 있다.

\subsection{RDA 자원유형 기술의 어려움}

$\mathrm{RDA}$ 초안의 자원유형에 대해 용어가 애매하 고 모든 자원 유형을 포괄하지 못한다는 의견이 있었으며, 용어의 갱신을 통해 'video disc'와 같
은 용어가 추가되기도 하였다. 따라서 RDA 자 원유형 리스트는 완전한 것이 아니며, 개방형으 로 계속적으로 변화할 것이다(Seikel \& Steele 2011).

RDA Test Coordinating Committee(2011) 에서 $\mathrm{RDA}$ 에 대한 전반적인 조사를 실시하였 다. 자원유형 기술의 변화에 대해서는 긍정적 인 의견도 있었으나, 일부 사서들은 $\mathrm{GMD}$ 를 삭 제하고, 336, 337, 338 태그에 내용, 매체, 용기 의 자원유형 기술하는 것에 대해 불만족하였다. 왜냐하면 자원유형 기술의 변화는 온라인목록 디스플레이에 명백한 영향을 줄 수 있기 때문 이었다.

사서들은 자원유형 기술에 대해 다음과 같이 제안하였다.

- 33X 용어는 실질적으로 일상적인 관습 (common usage) 을 반영해야 한다.

- 33X의 경우 여러 세트가 있을 때 관련 요 소를 연계할 수 있도록 묶어서 디스플레 이하는 방안이 필요하다.

- 내용/매체/용기는 GMD 리스트를 갱신 하되, Blu-Ray, Wii game 등과 같이 일 상적 관습으로 많이 이용되는 용어를 반 영해야 한다.

$\mathrm{RDA}$ 자원유형 기술시 사서가 기술하기 어려 운 유형은 〈표 1)과 같이 컴퓨터프로그램〉 2 차 원동영상 $>3$ 차원형태> 음성(spoken word) 순 으로 나타났다. 컴퓨터프로그램은 다음의 문제 점이 제기되었다. 첫째, 게임과 같은 컴퓨터멀티 미디어 자원을 위한 별도의 내용유형이 필요하 다. 둘째, 일반 비디오게임과 컴퓨터멀티미디어 
〈표 1〉RDA규칙 적용시 포맷별 어려움의 응답 비율

\begin{tabular}{l|c|c}
\hline \multicolumn{1}{c|}{ 자원유형 } & 어려움 없음 & 어려움 있음 \\
\hline cartographic dataset & $63 \%$ & $38 \%$ \\
\hline cartographic image & $90 \%$ & $10 \%$ \\
\hline cartographic dataset & $53 \%$ & $47 \%$ \\
\hline computer program & $23 \%$ & $77 \%$ \\
\hline notated music & $74 \%$ & $26 \%$ \\
\hline performed music & $57 \%$ & $43 \%$ \\
\hline spoken word & $43 \%$ & $57 \%$ \\
\hline still image & $49 \%$ & $51 \%$ \\
\hline tactile notated movement & $100 \%$ & $0 \%$ \\
\hline tactile text & $67 \%$ & $33 \%$ \\
\hline tactile three-dimensional form & $100 \%$ & $0 \%$ \\
\hline text & $82 \%$ & $18 \%$ \\
\hline three-dimensional form & $38 \%$ & $63 \%$ \\
\hline two-dimensional moving image & $35 \%$ & $65 \%$ \\
\hline
\end{tabular}

※ 출처: RDA Test Coordinating Committee. 2011.

게임을 위한 내용유형이 필요하다. 셋째, 혼합 미디어 용기를 위한 용기유형의 갱신이 필요하 다. 예를 들어, DVD는 "video disc'와 'computer disc' 모두에 해당할 수 있기 때문이다. 넷째, 용 어측면에서 전자자원에 해당하는 모든 자원을 수용하지 못할 수 있다. 전자자원의 매체유형은 ‘컴퓨터’이고, 용기유형은 ‘온라인자원'이다. 특 히 온라인이라는 용어는 대부분의 전자자원이 가지지 않은 특성인 데이터 연결을 함축하고 있 기 때문에 다운로드 받은 파일의 경우 용기유형 으로 온라인자원을 선택하는 데 어려움이 있다.

\section{3. 자원유형 기술현황 사례조사}

\section{1 조사방법}

국내도서관에서 자료유형에 대한 입력 현황 과 요구를 구체적으로 파악하기 위해 대학도서
관 1곳을 선정하여, 비도서자료의 GMD 입력 데이터를 전수 조사하였다. 전수 조사는 해당 기관에서 $\mathrm{GMD}$ 기술의 전체 모습을 역사적으 로 살펴볼 수 있으며, 설문조사에서는 파악하 기 어려운 내용을 도출할 수 있는 장점이 있다. 우선 전체 장서를 대상으로 $245 \$ \mathrm{~h}$ 의 값을 모두 추출하는 프로그램을 작성하고 이를 적용 하여 해당하는 값을 추출한 후 동일 용어의 사 용 빈도를 통계적으로 처리하였다.

\section{2 처리결과 및 분석}

처리한 결과 〈표 2〉와 같이 자료유형으로 가 장 많은 것은 비디오녹화자료, 전자책이었다. 또한 사례도서관에서 자체적으로 고안한 용어 도 많이 사용되었다.

\subsection{1 다양한 용어 사용}

비디오녹화자료는 $\mathrm{KCR} 4$ 에 따르면 비디오녹 
〈표 2〉사례도서관에서 245\$h GMD에 사용한 자원유형 용어

\begin{tabular}{|c|c|c|c|}
\hline $245 \$ \mathrm{~h}$ 자료유형 용어 & 입력건수 & 용어 측면 & 참조리스트 \\
\hline Video CD & 1 & 용기 & 참조없음 \\
\hline DVD & 112 & 용기 & 참조없음 \\
\hline DVD Video & 1 & 내용+용기 & 참조없음 \\
\hline DVD 녹화자료 & 4 & 내용+용기 & 참조없음 \\
\hline DVD 비디오 & 1 & 내용+용기 & 참조없음 \\
\hline DVD자료 & 652 & 용기 & 참조없음 \\
\hline videorecording & 1,291 & 내용 & AACR2 \\
\hline 녹화자료 & 164 & 내용 & 참조없음 \\
\hline 비디오녹화자료 & 8,623 & 내용 & KCR4 \\
\hline 비디오레코딩 & 11 & 내용 & 참조없음 \\
\hline 비디오자료 & 442 & 용기 & 참조없음 \\
\hline 비디오 & 106 & 용기 & 참조없음 \\
\hline 비디오테잎 & 76 & 용기 & 참조없음 \\
\hline 시청각자료 & 11 & 내용 & 참조없음 \\
\hline 영화 & 2 & 내용 & KCR4 \\
\hline Digital Versatile Disk & 1 & 용기 & 참조없음 \\
\hline 디지털 비디오 디스크 & 1 & 용기 & 참조없음 \\
\hline 전자북 & 1 & 내용 & 참조없음 \\
\hline 전자책 & 7,965 & 내용 & 참조없음 \\
\hline soundrecording & 215 & 내용 & AACR2 \\
\hline 녹음자료 & 838 & 내용 & KCR4 \\
\hline 오디오북 & 1 & 내용 & 참조없음 \\
\hline 전자자료 & 52 & 내용 & KORMARC \\
\hline 전자자원 & 1 & 내용 & 참조없음 \\
\hline electronic resource & 1,888 & 내용 & AACR2 \\
\hline computer file & 439 & 내용 & 참조없음 \\
\hline 컴퓨터 파일 & 216 & 내용 & 참조없음 \\
\hline SLIDE & 49 & 용기 & AACR2 \\
\hline 슬라이드 & 2 & 용기 & KCR4 \\
\hline CD-ROM & 663 & 용기 & 참조없음 \\
\hline kit & 1 & 내용 & USMARC \\
\hline 마이크로자료 & 3 & 용기 & KCR4 \\
\hline
\end{tabular}

화자료 및 videorecording으로 기술해야 하지만, ‘비디오레코딩', ‘비디오자료', ‘비디오', ‘비디오 테잎, '시청각자료', '영화', 'Video CD', 'DVD', 'DVD Video', 'DVD 녹화자료', 'DVD 비디오', 'DVD자료, 'Digital Versatile Disk', '디지털 비
디오 디스크'의 다양한 용어를 사용하였다. 특 히 KCR4가 출판되기 전에는 자체적으로 생성 한 용어가 사용되었으며, 용어를 생성할 때 자 료의 용기와 그 내용을 동시에 기술하려는 경우 가 많았다. 
전자책은 현행 $\mathrm{KCR} 4$ 자료유형인 전자데이 터나 통합 KORMARC 리더/06의 전자자료라 는 용어를 사용해야 하지만 전자책 혹은 전자북 이라는 자체적으로 생성한 용어를 사용하였다. 이는 전자자료라는 용어로 전자책 고유의 자료 유형을 표현하기는 어렵기 때문에 전자책이라 는 별도의 용어를 사용하였다고 볼 수 있다. 특 히 전자책은 내용상으로는 텍스트이며, 용기로 는 전자자료이기 때문에 기존 $\mathrm{GMD}$ 방식의 자 원유형을 적용하기 어렵다.

녹음자료 혹은 soundrecording 은 용어의 변 형없이 올바르게 기술되었다. 단, $\mathrm{CD}$ 로 제작된 오디오북의 경우 화면없이 목소리만 제공되는 것으로 녹음자료로 볼 수 없어 오디오북이라는 별도 용어를 사용하였다.

전자자료는 전자자원이라는 유사한 용어도 함께 사용되었다. 컴퓨터파일은 전자자료라는 용어가 사용되기 전에 사용된 용어였다. 슬라이 드와 같이 특정자료종별 용어가 $\mathrm{GMD}$ 에 사용 되는 경우도 있었으며, $\mathrm{CD}-\mathrm{ROM}$ 과 같이 용기 를 나타내는 용어가 사용되기도 하였다.

위와 같이 다양한 용어의 사용은 KCR4나 KORMARC의 용어리스트로 자원유형을 표현 할 수 없기 때문에 자관에서 임의적으로 변형 하여 사용한 것으로 볼 수 있다. 특히 동영상자 료의 경우 비디오녹화자료라는 용어 대신 DVD 라는 용어를 사용하였는데 이는 기존에 사용한 비디오녹화자료가 DVD라는 용기를 표현하기 어렵기 때문에 이용자의 요구를 반영하여 변형 한 것으로 볼 수 있다. 따라서 자원유형 기술시 이러한 다양한 측면이 기술되도록 해야 할 것 이다.

\section{2 .2 용어 측면}

용어가 자원의 내용측면, 용기측면 중에서 어느 것을 기술하기 위한 것인지를 분석하였다. 원칙적으로 $245 \$ \mathrm{~h}$ 에는 내용을 표현해야 하지 만 용기 측면을 표현하는 용어를 사용한 경우가 많았다. 예를 들어, CD-ROM, Video CD, DVD, DVD Video, DVD 녹화자료 DVD 비디오 DVD 자료, Digital Versatile Disk, 디지털비디오디스 크, 슬라이드, 비디오자료, 비디오, 비디오테잎 등과 같이 자료의 내용 보다는 용기를 표현하려 는 경향이 있었다.

자원유형 중 내용과 용기 모두를 표현하는 경향도 있었는데, 'DVD Video', 'DVD 녹화자 료', 'DVD 비디오'의 경우는 내용 용어인 비디 오녹화자료와 DVD라는 용기를 동시에 표현하 려고 한 것이었다.

종합하면, GMD 기술 내용이 온라인목록 간 략화면에서 디스플레이되며, 이는 이용자의 자 료선정에 중요한 정보가 되기 때문에 $\mathrm{GMD}$ 에 내용과 용기를 모두 표현할 수 있도록 해야 할 것이다. 또한 용기 용어는 최신 경향에 맞으면 서 이용자의 검색요구에 적합하도록 변경되어 야 할 것이다.

\subsection{3 참조리스트}

원칙적으로 자원유형을 기술하기 위해서는 $\mathrm{KCR} 4$ 및 $\mathrm{KORMARC}$ 의 자원유형과 관련된 참조리스트를 사용해야 하지만, 자체적으로 고 안한 용어를 사용한 경우가 많았다.

사용한 용어의 참조리스트는 AACR2, KCR4 의 용어와 KORMARC, USMARC의 용어를 혼합하여 사용하였다.

이와 같이 용어 기술을 위해 리스트를 혼용하 
여 적용한 것은 각 리스트 마다 적합한 용어가 모두 갖춰져 있지 않기 때문이었다. 따라서 모 든 자원유형을 표현할 수 있는 통일된 참조리스 트가 개발되어야 할 것이다.

\section{3 종합분석}

사례조사를 바탕으로 자원유형 기술 시 다음 과 같은 사항이 고려되어야 할 것이다.

첫째, 자원유형 기술 시 내용과 용기를 모두 표현하는 방안이 필요하다. 또한 용기를 표현 하려는 용어도 이용자 검색요구에 맞게 최신 용어로 갱신되어야 할 것이다.

둘째, 참조리스트는 통일성 및 모든 자원유형을 모두 포괄할 수 있을 정도의 완전성이 요구된다.

\section{4. 자원유형 기술현황 및 $\mathrm{RDA}$ 자원유형 이해정도}

자원유형 기술에 대한 도서관의 현황을 파악 하고 의견을 조사하기 위해 국내 대학도서관중 장서수가 50 만권 이상을 소장한 50 개 기관을 선 정한 후 해당기관의 목록사서에게 설문을 발송 하였다. 설문기간은 6 월 7일부터 30 일까지 $\mathrm{KSDC}$ 를 이용한 전자설문을 실시하였으나, 회신율은
$36 \%$ 이었다. 기관의 자원유형 기술의 특성을 파 악하기 위해 기관당 1 명의 목록사서만을 대상 으로 설문하였다.

\section{1 인적사항}

목록업무를 담당하는 사서의 성별은 여자가 $94 \%$, 연령별로는 40 대의 비율이 $55 \%$ 를, 학력은 4 년대졸이 $66 \%$ 를 차지하였다. 목록부서 근무기 간은 5-10년 이상이 $55 \%$ 이며, 사서자격증은 2 급 정사서가 $61 \%$ 였다.

\section{2 자원유형 적용 현황}

동서 목록규칙으로 $72 \%$ 가 KCR4를, $27 \%$ 가 $\mathrm{KCR} 3$ 를 사용하며, 양서 목록규칙으로 $94 \%$ 가 $\mathrm{AACR} 2$ 를 사용하였다. MARC 유형으로 동서는 $66 \%$ 가 KORMARC을, $33 \%$ 가 통합KORMARC 을 사용하며, 양서는 $66 \%$ 가 MARC21을, $27 \%$ 가 USMARC을 이용하였다. 일부에서는 양서 를 $\mathrm{KCR} 4$, KORMARC으로 목록하기도 하였다 (〈표 3〉 참조).

하지만, 조사기관 중에서 자원유형 기술을 위 해 $\mathrm{GMD}, \mathrm{SMD}$ 를 자관에 맞게 확장하거나 용 어를 변경한 기관은 없었으며, 한정어를 추가하 여 기술하는 기관은 한 곳이었다.

〈표 3〉동서 양서 기술규칙

\begin{tabular}{c|c|c|c|c}
\hline & 목록규칙 & 비율 $(\%)$ & MARC & 비율(\%) \\
\hline \multirow{3}{*}{ 동서 } & KCR3 & $27.78 \%$ & KORMARC & $66.67 \%$ \\
\cline { 2 - 5 } & KCR4 & $72.22 \%$ & 통합KORMARC & $33.33 \%$ \\
\hline \multirow{3}{*}{ 양서 } & AACR2 & $94.44 \%$ & USMARC & $27.78 \%$ \\
\cline { 2 - 5 } & RDA & $0 \%$ & MARC21 & $66.67 \%$ \\
\cline { 2 - 5 } & 기타(KCR4) & $5.56 \%$ & 기타(KORMARC) & $5.56 \%$ \\
\hline
\end{tabular}


〈표 4〉GMD, SMD 기술시 참조하는 리스트

\begin{tabular}{c|c|c|c|c}
\hline & GMD & 비율(\%) & SMD & 비율(\%) \\
\hline \multirow{3}{*}{ 동서 } & KCR4 & $61.11 \%$ & KCR4 & $66.67 \%$ \\
\cline { 2 - 5 } & 통합 KORMARC & $33.33 \%$ & 통합 KORMARC & $33.33 \%$ \\
\cline { 2 - 5 } & 기타(KCR4, 통합 KORMARC) & $5.56 \%$ & 기타(KCR4, 통합 KORMARC) & $5.56 \%$ \\
\hline \multirow{4}{*}{ 양서 } & AACR2 & $33.33 \%$ & AACR2 & $33.33 \%$ \\
\cline { 2 - 5 } & MARC21 & $55.56 \%$ & MARC21 & $55.56 \%$ \\
\cline { 2 - 5 } & RDA & $0.00 \%$ & RDA & $0.00 \%$ \\
\cline { 2 - 5 } & 기타(AACR2, MARC21 / KCR4) & $11.11 \%$ & 기타(AACR2, MARC21 / KCR4) & $11.11 \%$ \\
\hline
\end{tabular}

자원유형 기술을 위한 $\mathrm{GMD}, \mathrm{SMD}$ 참조리스 트에 대한 질문에 동서는 $\mathrm{KCR} 4$ 를 $61 \%$, 통합 $\mathrm{KORMARC}$ 을 $33 \%$ 사용하고, $5 \%$ 의 기관에서 는 $\mathrm{KCR} 4$ 와 통합 KORMARC을 혼합하여 사 용하는 것을 조사되었다. 또한 양서의 경우는 MARC21의 자료유형 리스트를 $55 \%$ 기관에서 사용하고, $\mathrm{AACR} 2$ 를 $33 \%$ 사용하는 것으로 나 타났다(〈표 4〉 참조). 이외에도 양서의 경우 $\mathrm{AACR} 2, \mathrm{MARC} 21$ 을 혼합하여 사용하는 곳도 있었으며, KCR4를 사용하는 곳도 있었다.

자원유형 기술시 KCR4, 통합KORMARC 리 스트를 동시에 적용하거나, 양서 자원유형 기술 시 AACR2, MARC21을 동시에 적용하는 것은 하나의 리스트를 참조하기에는 용어리스트가 충 분하지 않다는 것을 의미하는 것으로 용어에 대 한 변경 및 수정이 필요하다고 볼 수 있다.

\section{3 자원유형 기술의 문제점 및 방향}

$\mathrm{GMD}, \mathrm{SMD}$ 의 필요성에 대해서는 $90 \%$ 는 필요하다고 응답하였으나, 필요하지 않다고 답 한 경우도 $10 \%$ 를 차지하였다. $\mathrm{GMD}, \mathrm{SMD}$ 의 필요성에 대한 개방형 질문에서는 이용자에게 정확한 정보를 제공하여 검색을 지원하는 측면
과 자원에 대한 사서의 기술 측면에서 필요성이 제기하였다.

검색의 측면에서 $\mathrm{GMD}, \mathrm{SMD}$ 는 이용자에게 매체에 대한 정보를 제공하고, 내용과 형태에 대해 인식할 수 있도록 하여 자원의 선정을 돕 는 것이다. 특히 동일 내용이지만 자료의 형태 가 다양해지고 있기 때문에 자원유형은 이용자 가 식별하기 편리하게 표현해야 한다.

기술의 측면에서 동일한 물리적 형식을 가진 자료에 대한 동일한 서지기술 형식을 적용하기 위 해 $\mathrm{GMD}, \mathrm{SMD}$ 의 정보가 필요하다. 이는 기술하 려는 자원의 유형에 따라 기술요소가 달라지기 때 문에 자원에 대한 정확한 이해가 필요한 것이다.

$\mathrm{GMD}, \mathrm{SMD}$ 기술시 수정되어야할 사항에 대 한 개방형 질문에 〈표 5 〉와 같이 용어자체의 문 제와 기술방식의 문제를 제기하였다.

우선 용어자체의 문제로 첫째, 용어는 자료 구분이 불분명하고, 이용자들에게 친숙하지 않 았다. 둘째, 새로운 매체가 출현하고, 자원의 유 형이 다양해지기 때문에 이러한 변화에 맞는 신규용어가 필요하였다.

기술방식에서는 자원유형의 중복기술이 가 능해야 한다는 것인데, 이는 용어의 다양한 측 면에 대한 기술의 필요성을 의미하는 것이다. 
〈표 5〉GMD, SMD 기술 시 수정사항

\begin{tabular}{|c|c|c|}
\hline \multicolumn{2}{|c|}{ 구분 } & 답변내용 \\
\hline \multirow[b]{2}{*}{ 용어 } & 기존용어 & $\begin{array}{l}\text { - 자료구분이 불분명함. 예를 들어, 비디오녹화자료와 영화 자료 구분이 어려움. } \\
\text { - 이용자들에게 친숙하지 않은 용어가 많아서 이용자들이 이해하기 힘들 것으로 예상됨. }\end{array}$ \\
\hline & 신규용어 & $\begin{array}{l}\text { - 새로운 매체나 구별이 필요한 매체를 기술할 때 고정된 용어로 불편함. } \\
\text { • 신규매체 출현 시 기술이 어려운 경우가 있음. } \\
\text { • 현실에 맞는 용어나 규칙 등이 상세하게 다루어져야 할 필요가 있음. } \\
\text { • 시대의 변화에 따라 발맞춰야 할 듯함. }\end{array}$ \\
\hline \multicolumn{2}{|c|}{ 기술방식 } & • 중복기술이 가능해야 함. \\
\hline
\end{tabular}

$\mathrm{GMD}, \mathrm{SMD}$ 용어리스트 변경에 대한 필요성 에서 기존용어로 충분히 사용가능하다는 답변 이 $11 \%$ 였으며, 새로운 변화가 필요하다는 답변 은 $88 \%$ 였다.

용어변경의 필요성에 답한 사서를 대상으로 변경의 방향에 대한 조사에서 〈그림 1)과 같이 구체적인 용어 포함 및 이용자가 이해하기 쉬운 용어로의 변경이 $62 \%$, 현행리스트에 포함된 용 어의 확장 및 수정이 $37 \%$ 로 나타났다.

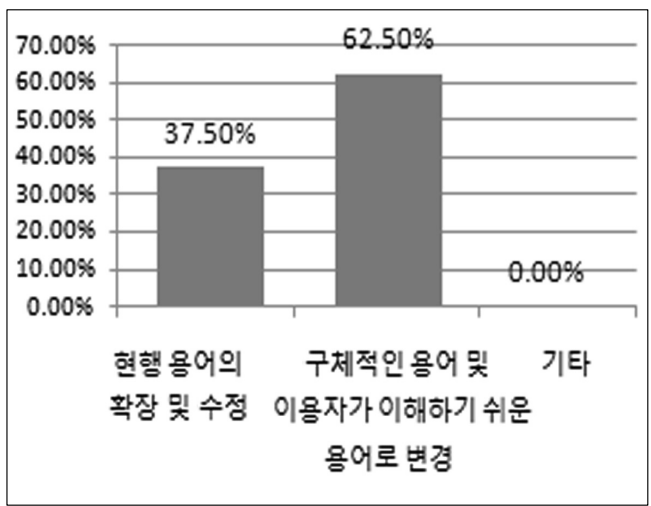

〈그림 1〉용어리스트 변경시 가장 필요한 사항

$\mathrm{GMD}$ 를 위한 새로운 기술방식으로 가장 적합 한 것은 〈그림 2〉와 같이 해당하는 $\mathrm{GMD}$ 를 모두 기술하도록 변경하는 것이 $38 \%$, 한정어 GMD 기술방식 적용이 $27 \%$, 기존의 기술 방식의 유지
$27 \%, \mathrm{GMD}$ 대신 MARC 코딩만을 사용하는 방 안이 $5 \%$ 로 나타났다.

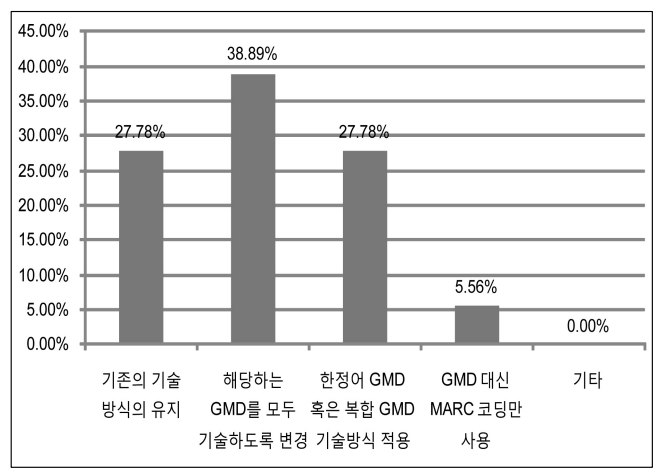

〈그림 2〉 GMD를 위한 새로운 기술방식

\subsection{RDA 자원유형 이해정도}

$\mathrm{RDA}$ 자원유형에 대한 이해 정도를 파악하고 자 사서를 대상으로 테스트한 결과 〈표 6〉과 같 이 마이크로피쉬, 온라인지도에 대해서는 정답 률이 높았고, 기상관측데이터, DVD수록 영화 에 대해서는 정답률이 낮았다.

DVD에 수록된 영화의 경우 내용유형은 2차 원동영상이고, 매체유형는 비디오, 용기유형은 비디오디스크이지만, 오답으로 내용유형에서 3 차원동영상, 입체기보움직임, 지도동영상을 선 택한 경우가 있었으며, 매체유형에서 컴퓨터, 
〈표 6〉RDA 자료유형에 대한 이해 정도

\begin{tabular}{|c|c|c|c|c|}
\hline & & 내용유형 & 매체유형 & 용기유형 \\
\hline \multirow{3}{*}{$\begin{array}{l}\text { DVD에 } \\
\text { 수록된 영화 } \\
\text { “써니” }\end{array}$} & 정 답 & 2차원동영상 & 비디오 & 비디오디스크 \\
\hline & 정답률 & $58 \%$ & $16 \%$ & $16 \%$ \\
\hline & 오 류 & $\begin{array}{c}\text { 3차원동영상 } \\
\text { 입체기보움직임 } \\
\text { 지도동영상 }\end{array}$ & $\begin{array}{l}\text { 컴퓨터 } \\
\text { 영사 }\end{array}$ & $\begin{array}{l}\text { 컴퓨터디스크 } \\
\text { 비디오카세트 }\end{array}$ \\
\hline \multirow{3}{*}{ 온라인지도 } & 정 답 & 지도이미지 & 컴퓨터 & 온라인자원 \\
\hline & 정답률 & $75 \%$ & $100 \%$ & $100 \%$ \\
\hline & 오 류 & $\begin{array}{c}\text { 지도데이터셋 } \\
\text { 컴퓨터데이터셋 }\end{array}$ & - & - \\
\hline \multirow{3}{*}{$\begin{array}{l}\text { 마이크로피쉬 } \\
\text { ERIC보고서 }\end{array}$} & 정 답 & 텍스트 & 마이크로폼 & 마이크로피쉬 \\
\hline & 정답률 & $91 \%$ & $100 \%$ & $100 \%$ \\
\hline & 오 류 & 컴퓨터데이터셋 & - & - \\
\hline \multirow{3}{*}{$\begin{array}{c}\text { 엑셀파일의 } \\
\text { 기상관측데이터 }\end{array}$} & 정 답 & 컴퓨터데이터셋 & 컴퓨터 & 온라인자원 \\
\hline & 정답률 & $58 \%$ & $91 \%$ & $58 \%$ \\
\hline & 오 류 & 텍스트 & 없음 & 컴퓨터카드 없음 \\
\hline
\end{tabular}

영사를, 용기유형에서 컴퓨터디스크, 비디오카 세트로 오답을 선택하였다.

분석결과 DVD가 다른 매체에 비해 많은 혼 란을 야기할 수 있었다. 왜냐하면 DVD는 매체 유형에서 비디오플레이어 뿐만 아니라 컴퓨터 에서도 구동할 수 있기 때문에 매체유형으로 컴퓨터를 선택하고, 용기유형으로 컴퓨터디스 크를 선택한 경우가 있었다.

온라인지도의 경우 내용유형은 지도이미지, 매체유형은 컴퓨터, 용기유형은 온라인자원이 지만, 오답은 내용유형에서 지도데이터셋, 컴퓨 터데이터셋이었고, 매체유형 및 용기유형에서 오답은 없었다. 특히 온라인지도라는 용어 때문 에 내용유형에서 컴퓨터데이터셋을 선택한 경 우가 있었으며, 측정된 지도데이터와 혼동하여 지도데이터셋을 선택하기도 하였다.

마이크로피쉬의 경우 내용유형이 텍스트, 매 체유형은 마이크로폼, 용기유형은 마이크로피
쉬이지만, 오답으로는 내용유형에서 컴퓨터데 이터셋이 선택되었으며, 매체유형과 용기유형 에서의 오답은 없었다.

엑셀파일로 작성된 기상관측데이터는 내용 유형이 컴퓨터데이터셋, 매체유형은 컴퓨터, 용 기유형은 온라인자원이지만, 오답으로는 내용 유형에 텍스트, 용기유형에 컴퓨터카드로 기재 한 경우가 있었다. 용기유형에서 온라인자원이 선택되지 않은 것은 해당 데이터가 온라인에 존 재하지 않는 것으로 생각하기 때문이다.

테스팅 후 RDA 내용유형, 매체유형, 용기유 형 용어에 대한 문제점으로 자원유형에 이용자 가 쉽게 접할 수 있는 용어가 필요하다고 조사 되었다. 예를 들어, 'DVD와 같이 쉽게 접하는 용어가 포함되어야 함, 'DVD의 경우 내용적인 면은 용어가 맞으나 부가적인 설명(영화라든 지)이 필요하고 매체측면에서도 $\mathrm{DVD}$ 를 기술 할 용어가 적당하지 않다', '엑셀자료의 경우 텍 
스트와 기상자료이기 때문에 이미지가 들어가 는 경우 이를 표현하도록 확장이 필요하며, 매 체의 경우도 정확히 표현하는 편이 이용자에게 인지가 쉬울 것 같다', '용어정리가 필요하다라 는 의견을 제시하였다.

\section{5 종합분석}

설문조사를 종합하면 다음과 같다. 첫째, 조 사대상 기관에서 동서는 목록규칙으로 $\mathrm{KCR} 4$, 입력형식은 KORMARC을 사용하며, 양서는 목록규칙으로 $\mathrm{AACR} 2$ 를 사용하고, 입력형식 은 MARC21을 사용하였다. 반면 자원유형 기 술을 위한 리스트 적용은 동서는 KCR4를, 양 서는 MARC21의 자원유형 리스트를 사용하였 다. GMD SMD를 자관에 맞게 확장하거나 용 어를 변경한 기관은 없었으며, 한 개 기관에서 한정어를 추가하여 기술하였다.

둘째, $\mathrm{GMD}, \mathrm{SMD}$ 의 필요성은 이용자에게 정확한 정보를 제공하기 위한 검색의 측면과 자 원 기술의 측면이었다.

셋째, 자원유형 기술시 문제점은 용어와 기술 방식에 관한 것이었다. 용어의 문제는 자료구분 이 불분명한 용어, 이용자가 사용하지 않는 용 어의 사용, 새로운 매체 출현에 따른 용어 갱신 이 이루어지지 않는 것이었다. 기술방식에서는 자원유형의 중복기술이 불가능한 점이 지적되 었다.

넷째, GMD, SMD 용어리스트 변경 시 필요 한 방향은 구체적인 용어 포함 및 이용자가 이 해하기 쉬운 용어로의 변경, 다음으로는 현행 리스트에 포함된 용어의 확장 및 수정이었다. 자원유형 기술시 용어 문제점과 용어리스트 변
경의 방향 모두 이용자 측면에서 용어를 고안하 는 것을 중시하였다.

다섯째, 자원유형 기술의 방안은 해당하는 $\mathrm{GMD}$ 를 모두 기술하도록 변경하는 것이었으 며, 다음으로 한정어와 함께 기술하는 방식 혹 은 기존 방식의 유지였다.

여섯째, RDA 자원유형 이해정도를 파악하 기 위한 테스팅에서 마이크로피쉬, 온라인지도 의 정답율은 높았으나, 기상관측데이터, DVD 영화의 정답률이 매우 낮았다. 특히, 매체유형 과 용기유형 보다는 내용유형에서 많은 오류를 범하고 있어, $\mathrm{RDA}$ 자원유형 용어가 쉽지 않음 을 보여주는 것이었다.

일곱째, RDA 용어의 방향성에서 내용, 매체, 용기 리스트에 대해서 이용자가 쉽게 접할 수 있는 용어가 포함되고, 이미지와 엑셀파일이 포 함된 자료와 같이 여러 자료가 혼합된 자료를 기술하는 방안이 필요하겠다.

\section{5. $\mathrm{RDA}$ 자원유형 적용 제안}

\section{1 원칙 및 방향}

자원유형 용어 및 기술의 기본 방향은 국제적 인 용어리스트에 부합해야 하며, FRBR 구현이 가능해야 할 것이다. 이에 따라 $\mathrm{RDA}$ 의 용어리 스트를 참조하되, 국내의 상황에 적합하도록 수 정 적용하고자 한다. 국내의 상황에 맞추기 위 해 3,4 장의 사례조사 및 설문조사를 바탕으로 다음과 같은 측면을 고려하였다.

첫째, 자원유형을 위한 참조리스트의 통일성 및 가능한 모든 자원유형을 모두 포괄할 수 있 
어야 한다. 이를 위해 사례연구와 설문조사에서 기술하기 어려운 자료로 제시된 전자북, 오디오 북, 닌텐도wii 게임을 수용하도록 하였다.

둘째, 새로운 변화에 맞게 최신의 용어가 적 용되어야 하고, 이용자의 요구를 반영할 수 있 는 용어가 반영되어야 한다. 특히 내용유형은 큰 변경이 이루어지지 않지만 용기유형은 시대 에 맞게 변경이 필요하기 때문에 최신 용어로 갱신하였다.

셋째, 용어의 다양한 측면을 기술할 수 있는 방안이 모색되어야 한다. 따라서 자원유형을 기술할 경우 내용, 매체, 용기 유형을 모두 기술 하는 $\mathrm{RDA}$ 의 방식을 적용하였다.

\section{2 자원의 내용유형}

자원의 내용유형은 FRBR 개념모형의 표현 형 식별을 위한 데이터 요소로 필수 기술사항이 다. RDA 내용유형 용어의 경우 캐릭터, 감각유 형, 차원, 움직임의 측면을 결합하여 체계적으 로 고안된 용어라고 할 수 있다. 특히, 지도와 관련한 내용유형이 세분화되었고, 비디오녹화 자료와 영화를 통합하였다. RDA는 FRBR 구 현이 가능하도록 개정되었고, 자원유형도 이를 반영하고 있어, 본 연구에서는 $\mathrm{RDA}$ 를 참조하 여 용어를 제안하였다.

제안한 내용유형은 〈표 7〉과 같이 RDA의 내용유형을 가능한 그대로 사용하되, 컴퓨터게 임을 추가하여 내용유형을 세분화하였다. 따라 서, 지도를 지도데이터셋, 지도이미지, 지도동 영상, 지도촉감이미지, 지도촉감3차원형태, 지 도3차원형태로 구분하고, 컴퓨터는 '전자'라는 용어대신 컴퓨터데이터셋, 컴퓨터프로그램, 컴
퓨터게임으로 구분하였다. 입체자료를 3 차원형 태와 촉감 3 차원형태로 구분하고, 동영상은 2 차 원동영상, 3 차원동영상으로 나누었다. 화상자 료의 경우 이미지라는 용어를 이용자가 더 친 숙하게 생각하여 이미지, 촉감이미지로 구분하 고, 악보를 악보와 촉감악보로, 녹음자료는 연 주음악과 소리로 구분하였다. 강연 등의 자료 를 음성으로 추가하고, 텍스트와 촉감텍스트로 제안하였다. 이에 따라 전자북의 내용유형은 텍스트이며, 오디오북은 음성, 닌텐도게임은 컴 퓨터게임으로 구분할 수 있다.

〈표 7〉RDA 내용유형과 내용유형(안) 비교

\begin{tabular}{|c|c|}
\hline RDA 내용유형 & 내용유형(안) \\
\hline $\begin{array}{l}\text { cartographic dataset } \\
\text { cartographic image } \\
\text { cartographic moving image } \\
\text { cartographic tactile image } \\
\text { cartographic tactile 3-dimensional } \\
\quad \text { form } \\
\text { cartographic 3-dimensional form }\end{array}$ & $\begin{array}{l}\text { 지도데이터셋 } \\
\text { 지도이미지 } \\
\text { 지도동영상 } \\
\text { 지도촉감이미지 } \\
\text { 지도촉감3차원형태 } \\
\text { 지도3차원형태 }\end{array}$ \\
\hline $\begin{array}{l}\text { computer dataset } \\
\text { computer program }\end{array}$ & $\begin{array}{l}\text { 컴퓨터데이터셋 } \\
\text { 컴퓨터프로그램 } \\
\text { 컴퓨터게임 }\end{array}$ \\
\hline $\begin{array}{l}\text { 3-dimensional form } \\
\text { tactile 3-dimensional form }\end{array}$ & $\begin{array}{l}\text { 3차원형태 } \\
\text { 촉감3차원형태 }\end{array}$ \\
\hline $\begin{array}{l}\text { 3-dimensional moving image } \\
\text { 2-dimensional moving image }\end{array}$ & $\begin{array}{l}3 \text { 차원동영상 } \\
2 \text { 차원동영상 }\end{array}$ \\
\hline $\begin{array}{l}\text { still image } \\
\text { tactile image }\end{array}$ & $\begin{array}{l}\text { 이미지 } \\
\text { 촉감이미지 }\end{array}$ \\
\hline $\begin{array}{l}\text { notated movement } \\
\text { tactile notated movement }\end{array}$ & $\begin{array}{l}\text { 기보움직임 } \\
\text { 촉감기보움직임 }\end{array}$ \\
\hline $\begin{array}{l}\text { notated music } \\
\text { tactile notated music }\end{array}$ & $\begin{array}{l}\text { 악보 } \\
\text { 촉감악보 }\end{array}$ \\
\hline $\begin{array}{l}\text { performed music } \\
\text { sounds }\end{array}$ & $\begin{array}{l}\text { 연주음악 } \\
\text { 소리 }\end{array}$ \\
\hline spoken word & 음성 \\
\hline $\begin{array}{l}\text { tactile text } \\
\text { text }\end{array}$ & $\begin{array}{l}\text { 촉감텍스트 } \\
\text { 텍스트 }\end{array}$ \\
\hline
\end{tabular}




\section{3 자원의 용기유형}

자원의 용기유형은 FRBR 개념모형의 구현 형 식별을 위한 데이터 요소이다. 제안한 용기 유형을 RDA 용기유형과 비교한 결과는 〈표 8〉 과 같다. 사례조사 및 설문조사를 바탕으로 새 로운 매체를 수용하는 용어 및 이용자의 관행을 반영한 용어를 추가하였다. 이에 따라 매체유형 이 컴퓨터, 비디오인 경우 DVD, CD-ROM, 블 루레이(Blu-Ray)를 추가하고, 매체유형이 오 디오인 경우 $\mathrm{CD}-\mathrm{ROM}$ 만 추가하였다. 또한 매 체유형이 컴퓨터인 경우 컴퓨터파일을 추가하 여, '다운로드한 MP3 파일'과 같이 온라인자 원으로 취급하기 어려운 자원을 기술할 수 있 도록 하였다. 이에 따라 전자북의 용기유형은 온라인자원이며, 오디오북은 $\mathrm{CD}-\mathrm{ROM}$, 닌텐 도게임도 $\mathrm{CD}-\mathrm{ROM}$ 으로 기술할 수 있다.

〈표 8〉 RDA 용기유형과 용기유형(안) 비교

\begin{tabular}{l|l}
\hline \multicolumn{1}{c|}{ RDA 용기유형 } & \multicolumn{1}{|c}{ 용기유형(안) } \\
\hline & 컴퓨터카드 \\
computer card & 컴퓨터칩카트리지 \\
computer chip cartridge & DVD \\
computer disc & Blu Ray \\
computer disc cartridge & CD-ROM \\
computer tape cartridge & 컴퓨터디스크카트리지 \\
computer tape cassette & 컴퓨터테잎카트리지 \\
computer tape reel & 컴퓨터테잎카세트 \\
online resource & 컴퓨터테잎릴 \\
& 온라인자원 \\
& 컴퓨터파일 \\
\hline stereograph card & 스테레오그라프카드 \\
stereograph reel & 스테레오그라프릴 \\
\hline & 비디오카트리지 \\
video cartridge & 비디오카세트 \\
videocassette & DVD \\
videodisc & Blu Ray \\
videotape reel & CD-ROM \\
& 비디오테잎릴 \\
\hline
\end{tabular}

\begin{tabular}{|c|c|}
\hline RDA 용기유형 & 용기유형(안) \\
\hline $\begin{array}{l}\text { film cartridge } \\
\text { film cassette } \\
\text { film reel } \\
\text { film roll } \\
\text { filmslip } \\
\text { filmstrip } \\
\text { filmstrip cartridge } \\
\text { overhead transparency } \\
\text { slide }\end{array}$ & $\begin{array}{l}\text { 필름카트리지 } \\
\text { 필름카세트 } \\
\text { 필름릴 } \\
\text { 필름롤 } \\
\text { 필름슬립 } \\
\text { 필름스트립 } \\
\text { 필름스트립카트리지 } \\
\text { 오버헤드트랜스페어런시 } \\
\text { 슬라이드 }\end{array}$ \\
\hline $\begin{array}{l}\text { card } \\
\text { flipchart } \\
\text { object } \\
\text { roll } \\
\text { sheet } \\
\text { volume }\end{array}$ & $\begin{array}{l}\text { 카드 } \\
\text { 플립차트 } \\
\text { 오브젝트 } \\
\text { 롤 } \\
\text { 쉬트 } \\
\text { 볼륨 }\end{array}$ \\
\hline $\begin{array}{l}\text { aperture card } \\
\text { microfiche } \\
\text { microfiche cassette } \\
\text { microfilm cartridge } \\
\text { microfilm cassette } \\
\text { microfilm reel } \\
\text { microfilm roll } \\
\text { microfilm slip } \\
\text { microopaque }\end{array}$ & $\begin{array}{l}\text { 아파춰카드 } \\
\text { 마이크로피쉬 } \\
\text { 마이크로피쉬카세트 } \\
\text { 마이크로필름카트리지 } \\
\text { 마이크로필름카세트 } \\
\text { 마이크로필름릴 } \\
\text { 마이크로필름롤 } \\
\text { 마이크로필름 슬립 } \\
\text { 마이크로오파크 }\end{array}$ \\
\hline microscope slide & 현미경슬라이드 \\
\hline $\begin{array}{l}\text { audio cartridge } \\
\text { audio cylinder } \\
\text { audio disc } \\
\text { audio roll } \\
\text { audiocassette } \\
\text { audiotape reel } \\
\text { sound-track reel }\end{array}$ & $\begin{array}{l}\text { 오디오카트리지 } \\
\text { 오디오실린더 } \\
\mathrm{CD}-\mathrm{ROM} \\
\text { 오디오롤 } \\
\text { 오디오카세트 } \\
\text { 오디오테잎릴 } \\
\text { 사운드트랙릴 }\end{array}$ \\
\hline
\end{tabular}

※ 굵은 글씨체는 기존 $\mathrm{RDA}$ 용기 용어에서 추가 및 변경된 것임.

\section{4 자원유형 기술방식 및 화면출력}

$\mathrm{RDA}$ 내용유형, 매체유형, 용기유형 용어는 MARC21의 336, 337, 338 태그에 각각 기술한 다. 또한 디스플레이에 대한 세부적인 사항은 규정되지 않았으나, 자원유형 용어는 이용자의 자원 선택의 기준이 되기 때문에 모두 표시하되 새로운 디스플레이 형태가 되어야 할 것이다. 
〈표 9〉RDA 자원유형 기술방식 및 화면출력

\begin{tabular}{l|l}
\hline & \multicolumn{1}{c}{ 기술방식 및 디스플레이 } \\
\hline \multirow{3}{*}{ 기술방식 } & 336 \#\# \$a텍스트 \$2rdacontent \\
& 337 \#\# \$a컴퓨터 \$2rdamedia \\
& 338 \# \$aCD-ROM \$2rdacarrier \\
\hline 화면출력 & {$[$ 내용 : 텍스트 / 매체 : 컴퓨터 / 용기 CD-ROM] } \\
\hline
\end{tabular}

〈표 9〉와 같이 내용, 매체, 용기를 336,337 , 338 에 각각 기술한다. 화면출력도 이용자 친화 적으로 내용, 매체, 용기를 함께 디스플레이하도 록 해야 할 것이다. 따라서 전자북은 [내용: 텍 스트 / 매체: 컴퓨터 / 용기: 온라인자원]으로, 오디오북 [내용: 음성 / 매체: 오디오 / 용기: $\mathrm{CD}-\mathrm{ROM}$ ], wii 닌텐도게임은 [내용: 컴퓨터게 임 / 매체: 컴퓨터 / 용기: $\mathrm{CD}-\mathrm{ROM}$ ]과 같이 디스플레이 될 것이다.

\section{6. 결 론}

$\mathrm{RDA}$ 자원유형은 기존 $\mathrm{GMD}, \mathrm{SMD}$ 의 한계 를 해결하기 위해 다양한 연구를 바탕으로 최근 에 개발되었으며, 이는 앞으로 전세계 목록분야 에 많은 영향을 줄 것이다. 국내에서는 자원유 형에 대한 문제점은 제기되었으나 실질적인 개 정으로까지 이어지지 못하고 있다.

이에 본 연구에서는 RDA의 자원유형에 대 한 국내 적용가능성을 모색하고자 하였다. 이를 위해 사례조사 및 국내 대학도서관 사서를 대
상으로 자원유형 기술 현황, 자원유형기술의 문 제점과 방향, $\mathrm{RDA}$ 자원유형의 이해정도를 조 사하였다. 이를 통해 국내 상황을 고려한 자원 유형 기술 방안을 제안하였다.

제안한 자원유형 리스트는 RDA를 참조하 되, 사례조사 및 설문조사를 기반으로 이용자 측면의 용어를 반영하고자 하였다. 내용유형에 서는 컴퓨터게임을 추가하고, 용기유형에서는 이용자 측면의 용어를 수용할 수 있도록 DVD, Blu-Ray, CD-ROM, 컴퓨터파일의 용어를 추 가하였다.

자원유형 기술을 위해 MARC21과 같이 KORMARC 태그를 새로 생성해야 하며, 화면 출력에서는 FRBR을 위해 RDA 디스플레이 방 식을 적용해 내용, 매체, 용기를 함께 디스플레이 하도록 제안하였다.

본 연구는 사서를 대상으로 RDA 자원유형 이해정도를 파악하기 위한 테스트를 실시하여 $\mathrm{RDA}$ 자원유형의 국내 적용 가능성을 모색하였 다. 앞으로 이용자를 대상으로 RDA 용어의 적 합성에 대한 연구도 수행되어야 할 것이다. 


\section{참 고 문 헌}

이미화. 2011. KCR4 GMD 및 $\mathrm{SMD}$ 기술의 새 로운 방향 모색. 『한국도서관 - 정보학회 지』, 42(2): 237-255.

한국도서관협회. 2003.『한국목록규칙』, 제4판. 서울: 한국도서관협회.

Chapman, A. 2006. "RDA: A new international standard." Ariadne, 49(OCT. 2006). [cited 2011.7.10].

〈http://www.ariadne.ac.uk/issue49/c hapman $\rangle$.

Chung, H. H. 2001. "User-friendly audiovisual material cataloging at Westchester County Public Library System." Cataloging \& Classification Quarterly, 31(3/4): 313325.

Delsey, T. 1998. The Logical Structure of the Anglo-American Cataloguing Rules. [cited 2011.3.10]. $\langle$ http://www.rda-jsc.org/docs/aacr.p df $\rangle$.

Delsey, T. 2006. Categorization of Content and Carrier Terms in RDA. [cited 2011.4.5]. $\langle$ http://www.rda-jsc.org/docs/5rda-p arta-categorization.pdf $\rangle$.

Dunsire, G. 2007. "Distinguishing content from carrier: the RDA/ONIX framework for resource categorization." D-Lib Magazine, 13(1/2). [cited 2011.3.10]. $\langle$ http://www.dlib.org/dlib/january07 /dunsire/01dunsire.html〉.
GMD/SMD Working Group. 2005. Content and Carrier Terms in RDA. [cited 2011. 3.20].

$\langle$ http://opus.bath.ac.uk/17891/〉.

Green, R. and N. Fallgren. 2007. "Anticipating new media: A faceted classification of material types." In Proceedings North American Symposium on Knowledge Organization(Toronto: Ontario, 2007): 87-99. [cited 2011.5.9]. 〈http://dlist.sir.arizona.edu/arizona/bit stream/10150/106475/1/63_Green.pdf〉.

Guerrini, M. 2004. "GMD: Its function and its history." Cataloging \& Classification Quarterly, 38(2): 61-74.

Hider, P. 2009a. "A Comparison between the RDA taxonomies and end-user categorizations of content and carrier." Cataloging \& Classification Quarterly, 47(6): 544-560.

Hider, P. 2009b. "Library resource categories and their possible groupings." Australian Academic \& Research Libraries, 40(2): 105-115.

JSC for Development of RDA. 2011. RDA: Resource Description and Access. ALA. JSC Format Variation Working Group. 2003. Joint Steering Committee for the Revision of AACR(JSC) Format Variation Working Group. [cited 2011.5.5]. 
$\langle$ http://www.loc.gov/marc/marbi/20 03/2003-report01.html .

Kiorgaard, D. 2006. RDA/ONIX Framework for Resource Categorization.

[cited 2011.3.15].

〈www.loc.gov/marc/marbi/2007/5cha ir10.pdf $\rangle$.

RDA Test Coordinating Committee. 2011. Report and Recommendations of the U.S. RDA Test Coordinating Committee. [cited 2011.6.30].

〈http://www.loc.gov/bibliographic-fu ture/rda/rdatesting-finalreport-20june 2011.pdf $>$.

Seikel, M. and T. Steele. 2011. "How MARC has changed: the history of the format and its forthcoming relationship to RDA." Technical Services Quarterly, 28: 322334.
Tillett, B. 2001. General Material Designations (GMDs). [cited 2011.4.5].

$\langle$ http://www.rda-jsc.org/docs/gmd.p df $>$.

Weihs, J. 2000. General Material Designations in the Twenty-first century. [cited 2011.3.10]. $\langle$ http://www.olacinc.org/drupal/capc_ files/gmd.pdf $>$.

Weihs, J. and L. Howarth. 2008. "Designating materials: from "germane terms" to element types." Cataloging \& Classification Quarterly, 45(4): 3-24.

Yee, M. M. 2007. "FRBR and moving image materials: content versus carrier." In Understanding FRBR(CT: Libraries Unlimited, 2007) : 117-130. [cited 2011.3.10]. $\langle$ http://repositories.cdlib.org/postprint s/2648>. 